\title{
EL ACTO DE CONSUMO COMO HECHO \\ Y LA RESPONSABILIDAD CIVIL*
}

\section{EdUARdo ANTONIO FUENZALIDA ROBLEDO**}

RESUMEN: El fundamento de la responsabilidad civil que deriva de la Ley 19.496, dista de la que es posible fundar del contrato o la propia que nace de un hecho ilícito culpable o doloso. Nuestra opinión es que ella emana de un hecho, el cual entendemos como la circunstancia misma de adquirir, usar o disfrutar para el consumo y que, como conjunto, no lo asociamos necesariamente a un acto jurídico, aunque puede serlo y también servir de presupuesto corriente para su calificación. La segunda parte analiza la responsabilidad civil que de ella deriva en sus aspectos centrales.

PALABRAS CLAVE: Responsabilidad; consumo; contrato; acto; hecho.

\section{THE ACT OF CONSUMPTION AS}

\section{A FACT AND CIVIL LIABILITY}

ABSTRACT: The basis of liability stemming from the Act 19.496 is far from possible founding of the contract or the torts. Our view is that it emanates from a fact, which we understand it as the circumstance itself to acquire, use or enjoy for consumption but overall, we do not necessarily assimilate this as a legal act or contract, although it might be and also serve as a common condition for its legal category. The second part analyzes the civil liability that derives from there, specifically in its main aspects.

KEY WORDS: Liability; consumption; contract; act; fact.

Fecha de recepción: 22 de junio de 2016.

Fecha de aceptación: 21 de abril de 2017.

** Abogado, Magíster en Derecho Privado, Universidad de los Andes (Chile). Correo electrónico: fuenzalida.robledo@gmail.com 
Sumario: Introducción. 1) Normativas sobre responsabilidad en la Ley 19.496. 2) El acto de adquirir, usar o disfrutar. 3) Fuente de la responsabilidad en el consumo. (3.1.) Sujetos intervinientes. (3.2.) Inexistencia de un factor subjetivo de imputación. (3.3.) Extensión de los daños. (3.4.) Causalidad. 4) Por qué no debemos acudir a las fuentes tradicionales. (4.1.) La hipótesis de incumplimiento contractual. (4.2.) Obligaciones legales y régimen extracontractual. Conclusiones.

\section{INTRODUCCIÓN}

La responsabilidad civil en Chile reposa, como regla, en el deber de reparar un daño. Si el fundamento de aquella es subjetivo hace que la víctima se enfrente a una dificultad ${ }^{1}$ adicional, aparte de probar los dańos, como es la de acreditar la culpa o dolo a quien le imputa ese detrimento. Para los efectos del derecho del consumo, en cambio, en muchos países se han sustituido los paradigmas tradicionales del derecho de daños ${ }^{2} y$, en lugar de centrarse en el autor del perjuicio, se traslada el reproche de responsabilidad hacia quien lo sufrió, bastando que este ocurra para que su autor, por mandato legal, esté obligado a indemnizarlo. Es decir, se impone la denominada responsabilidad estricta u objetiva.

Cuando se estudian los daños y el sistema general de responsabilidad civil en la Ley de Protección de los Derechos de los Consumidores, nos parece que parte de la doctrina nacional efectúa un encauce forzoso o excesivo a las normas del derecho civil, desconociendo la autonomía ${ }^{3}$ que esta nueva disciplina jurídica exhibe en Chile, pese a no contar nuestro país con un Código del Consumo como sí ocurre en la legislación brasileña o peruana ${ }^{4}$, de este lado del continente, y en países de la Unión Europea, como España.

1 Abeliuk, René (2008) Las Obligaciones, Tomo I. Santiago: Editorial Jurídica de Chile, quinta edición actualizada, p. 170; Tomasello Hart, Leslie (1994) Estudios de derecho privado. Valparaíso: EDEVAL, p. 65.

2 Dírz-Picazo, Luis (1979) Responsabilidad civil hoy. Madrid: Anuario de derecho civil, tomo 32 fascículo IV, octubre-diciembre, pp. 727, 732-734.

3 Por todos, VV.AA. (Pinochet Olave, Ruperto (2007) ¿Integra el derecho de consumo el derecho civil, el derecho mercantil o conforma una disciplina jurídica autónoma? En Estudios de Derecho Civil III, Jornadas Nacionales de derecho civil Valparaíso. Santiago: Editorial LegalPublishing; Rodríguez Grez, Pablo (2014) "¿Puede hablarse de un derecho del consumidor?” (Primera parte). Revista Actualidad Jurídica Nº 29. Santiago: Universidad del Desarrollo, Facultad de Derecho.

4 Manzano Chávez, Liliana (2008) Defensa del consumidor. Análisis comparado de los casos de Argentina, Brasil, Chile y Uruguay. Santiago: Friedrich Ebert Stiffung. Disponible en: http:// library.fes.de/pdf-files/bueros/chile/05458.pdf, en línea [fecha de visita 21 de junio de 2016], pp. 4-8. 
Por otro lado, a partir del estudio de la casuística jurisprudencial de responsabilidad civil en la Ley 19.496 hemos advertido que el análisis contractual como génesis de aquella no genera conformidad, en razón de que existen hechos materiales al margen de un contrato de consumo que sí producen responsabilidad. Entonces la cuestión no resulta ser pacífica si solo nos quedamos - para el establecimiento de un sistema general de responsabilidad civil- con la figura del contrato; tenemos que ir más allá de aquel, o mejor dicho, ex ante.

Como conclusión básica de este estudio se afirma que la ley de Protección de los Derechos de los Consumidores, $\mathrm{N}^{\circ} 19.496$ (en adelante LDPC o la Ley), ofrece un sistema de responsabilidad civil distinto a los tradicionales, toda vez que no existe una identificación plena en sus presupuestos de operación. Atribuimos a la errada técnica legislativa de dicha ley, un efecto en el enfoque que han dado los autores nacionales y tribunales del país cuando se ha investigado y resuelto la responsabilidad civil en el derecho del consumo. Si ponemos, en cambio, énfasis en los principios que inspiran a aquel, llegamos a otras conclusiones. Ello implicará finalmente que somos respetuosos y coherentes del rol protector que inspira y persigue la Ley.

Creemos ciertamente que, si bien la LDPC presenta una redacción incompleta, carente de orden e incluso en partes confusa, posee principios inspiradores (transparencia, confianza, buena fe objetiva ${ }^{5}$, protección de la parte débil de la relación $\left.{ }^{6}\right)^{7}$ que hacen una diferencia grosso modo con respecto a las normas del derecho civil $^{8}$. En esta línea estuvo tiempo

5 Reconocida expresamente en la letra g) del artículo 16 de le Ley 19.496 y doctrinariamente en su análisis de cláusulas abusivas Rodríguez cuando afirma que "esta norma constituye una clara expresión de la llamada buena fe objetiva, puesto que dice relación con el comportamiento del sujeto a contratar" (Rodríguez (2014) 193).

6 En este sentido, del propio título de la norma en análisis y manifestación expresa en el artículo $4^{\circ}$ que prescribe la irrenunciabilidad anticipada de los derechos del consumidor. Por su parte Pinochet indica que la normativa que inspira el derecho del consumo apunta a "estructurar un sistema de protección al consumidor, considerando a este último como la parte débil de la relación contractual, frente a la parte fuerte, el profesional" (Pinochet (2007) 73-93). En igual sentido, Aimone señala "La ley pues o más precisamente el derecho, como en muchas otras ocasiones y circunstancias, se pone al lado del débil para que, de tal modo se restablezca la igualdad, que es la nota más importante de la justicia”. (Armone Gibson, Enrique (2013) Protección de derechos del consumidor. Santiago: LegalPublishing-Thomson Reuters, p. 5).

7 Baraona GonzÁlez, Jorge (2014) “Regulación contenida en la ley 19.496 sobre protección de los derechos de los consumidores y las reglas del código civil y comercial sobre contratos: un marco comparativo". Revista Chilena de Derecho, N 41.2, pp. 384-389.

$8 \quad$ Así ha opinado Kemelmajer al afirmar que "Estamos viviendo la era de la descodificación; existen leyes especiales para actividades o temáticas que se van desgajando del código civil: medio ambiente, consumidores, etc. De este modo, cada ley va creando su propio microsistema, cuya inserción en el macrosistema no siempre es de fácil solución”. Luego agrega que: 
atrás la Corte Suprema chilena al fallar el caso Cencosud ${ }^{9}$, instancia en la que se razonó que para resolver las controversias suscitadas en relaciones reguladas en la Ley del Consumidor debe atenderse a la "peculiaridad de sus principios".

Así, esta investigación tiene como punto de inicio el análisis del hecho del consumo, a partir del cual podrán entenderse variados aspectos que la Ley del Consumidor trata, particularmente -en lo que nos interesa-, el régimen legal de responsabilidad civil general que opera en esta importante disciplina.

\section{1) NORMATIVAS SOBRE RESPONSABILIDAD CIVIL EN LA LEY 19.496}

El tratamiento de la responsabilidad civil en la LDPC por la doctrina nacional ${ }^{10}$ tiene como factor de partida las normas del derecho civil, matizado en ciertos casos por algunos autores ${ }^{11}$ que reconociendo autonomía o especialidad al derecho del consumo, han estimado cierta peculiaridad en dicho sistema.

Enfrentando la tarea de dilucidar qué régimen -pensando o centrándonos en el hecho mismo de consumir- se aplica en la LDPC, si contractual o extracontractual, se advierten efectivamente ciertas semejanzas con uno u otro sistema en determinados casos ${ }^{12}$, es más, puntualmente lo regula como -entre otros- en eventos de demanda colectiva, cláusulas abusivas o del artículo 23 de la Ley, no obstante, afirmamos que el ré-

\footnotetext{
"En el ámbito de los derechos de los consumidores, ¿tenemos que hacer lo que hizo Chile, que reguló la responsabilidad por productos sobre base subjetiva, o por el contrario, se trata de una responsabilidad especial que merece ser regida por principios especiales?". (KemeLmajer Carlucci, Aída (2001) "Los dilemas de la responsabilidad civil". Revista Chilena de Derecho, Vol. 28, № 44), p. 677).

9 Corte Suprema. 24 de abril de 2013. Rol 12.355-2011. "Sernac con Cencosud". Disponible en http://suprema.poderjudicial.cl/SITSUPPORWEB/InicioAplicacion.do [fecha de visita 21 de junio de 2016] p. 38.

10 VV.AA. (Corral Talciani, Hernán (2011) Responsabilidad por Productos Defectuosos, Análisis y Propuestas para El Derecho Civil y de Consumo en Chile. Santiago: Editorial AbeledoPerrot-LegalPublishing, p. 362; RodríGuez, (2014)).

11 VV.AA. (Barrientos Camus, Francisca (2014) "La articulación de remedios en el sistema de la responsabilidad civil del consumo". Revista de Derecho de la Pontificia Universidad Católica de Valparaíso, XLII) pp. 57-82; Caprile Biermann, Bruno (2006) Las acciones del comprador insatisfecho: el cumulo actual y la tendencia al deber de conformidad. Santiago: Editorial LexisNexis, pp. 629-650).

12 Como sucede con las garantías legales de los artículos 19 y 20 de la LDPC a propósito de las obligaciones del proveedor respecto de la obligación de entrega, véase BarRIENTos (2014) 65-66; o bien, en el caso del expendio de productos peligrosos que trata el artículo 45, que sería un caso de responsabilidad extracontractual en concepto de Corral (2011) pp. $95-110$.
} 
gimen de responsabilidad general en el derecho del consumo no encaja plenamente con aquellos. Para llegar a esta conclusión, resulta previo y necesario el reconocimiento del derecho del consumo como una rama nueva, especial y autónoma ${ }^{13}$, regido por principios diferentes de otras disciplinas del derecho.

La información que aparece en diversos artículos de la LDPC ${ }^{14}$ (así sucede con los artículos $1^{\circ} \mathrm{N}^{\circ} 3$ que consagra la información básica comercial; $3^{\circ}$ letra b) que indica como derecho básico del consumidor la información; $12^{\circ}$ en cuanto prescribe la obligación del proveedor de respetar los términos del ofrecimiento de un bien o servicio; $14^{\circ}$ para el caso de la venta de productos con alguna deficiencia, usados o refaccionados, entre otros) como deber y derecho del proveedor y consumidor respectivamente, no se orienta a la formación del consentimiento preciso y necesario en una relación contractual tradicional, sino que se atiende a la

13 Villalba Cuéllar, Juan Carlos (2009) Aspectos introductorios al derecho del consumo. Bogotá: Red de Revistas Científicas de América Latina y el Caribe, España y Portugal, pp. 77-94.

14 "Art. $1^{\circ} \mathrm{N}^{\circ}$ 3.- Información básica comercial: los datos, instructivos, antecedentes o indicaciones que el proveedor debe suministrar obligatoriamente al público consumidor, en cumplimiento de una norma jurídica.

Tratándose de proveedores que reciban bienes en consignación para su venta, estos deberán agregar a la información básica comercial los antecedentes relativos a su situación financiera, incluidos los estados financieros cuando corresponda.

En la venta de bienes y prestación de servicios, se considerará información comercial básica, además de lo que dispongan otras normas legales o reglamentarias, la identificación del bien o servicio que se ofrece al consumidor, así como también los instructivos de uso y los términos de la garantía cuando procedan.

Se exceptuarán de lo dispuesto en este inciso los bienes ofrecidos a granel.

La información comercial básica deberá ser suministrada al público por medios que aseguren un acceso claro, expedito y oportuno. Respecto de los instructivos de uso de los bienes y servicios cuyo uso normal represente un riesgo para la integridad y seguridad de las personas, será obligatoria su entrega al consumidor conjuntamente con los bienes y servicios a que acceden.

Art. $3^{\circ}$ letra b) El derecho a una información veraz y oportuna sobre los bienes y servicios ofrecidos, su precio, condiciones de contratación y otras características relevantes de los mismos, y el deber de informarse responsablemente de ellos;

Art. 12.- Todo proveedor de bienes o servicios estará obligado a respetar los términos, condiciones y modalidades conforme a las cuales se hubiere ofrecido o convenido con el consumidor la entrega del bien o la prestación del servicio.

Art. 14.- Cuando con conocimiento del proveedor se expendan productos con alguna deficiencia, usados o refaccionados o cuando se ofrezcan productos en cuya fabricación o elaboración se hayan utilizado partes o piezas usadas, se deberán informar de manera expresa las circunstancias antes mencionadas al consumidor, antes de que este decida la operación de compra. Será bastante constancia el usar en los propios artículos, en sus envoltorios, en avisos o carteles visibles en sus locales de atención al público las expresiones "segunda selección", "hecho con materiales usados" u otras equivalentes.

El cumplimiento de lo dispuesto en el inciso anterior eximirá al proveedor de las obligaciones derivadas del derecho de opción que se establece en los artículos 19 y 20, sin perjuicio de aquellas que hubiera contraído el proveedor en virtud de la garantía otorgada al producto." 
seguridad en el consumo ${ }^{15}$. Entendido lo anterior como la confianza que debe tener el consumidor en este mercado masificado, y que se traduce en que lo pretendido adquirir se conforme con lo ofertado por el proveedor ${ }^{16}$.

La LDPC chilena no trata la responsabilidad civil en forma sistemática, siendo variadas las disposiciones que se refieren a este instituto. Es así como regula inicialmente en su Título II párrafo $5^{\circ}$ la responsabilidad por incumplimiento, sin embargo, para el análisis del estatuto de responsabilidad civil que opera debe ser estudiada la ley en su conjunto, pues producto de una errada técnica legislativa como acusamos existe una dispersión de normas que, solo estudiadas globalmente, permitirán entender el verdadero régimen aplicable al hecho de consumir.

$\mathrm{Al}$ efecto, el artículo $3^{\circ}$ letra e) ${ }^{17}$, antes del citado párrafo $5^{\circ}$, prescribe como derecho básico del consumidor la reparación e indemnización adecuada y oportuna de todos los dańos materiales y morales en caso de incumplimiento de cualquiera de las obligaciones contraídas por el proveedor. Esta norma fue modificada el año 2004 por la Ley $N^{\circ} 19.955$, habiéndose sustituido la expresión "en caso de incumplimiento a lo dispuesto en esta ley" por la nueva "en caso de incumplimiento de cualquiera de las obligaciones contraídas por el proveedor". Esta enmienda, relevante por cierto, careció de un análisis agudo por parte de los legisladores cuando fue discutido el proyecto modificatorio a la LDPC, consignándose solo la opinión del Diputado Tuma ${ }^{18}$, en sesión de sala de 13 de mayo de 2003, quien precisa que: "la obligación de indemnizar los perjuicios al consumidor nace del incumplimiento de una obligación contractual del proveedor, y no solo del incumplimiento de la ley, como lo establece la normativa vigente." Lo anterior, implica comprender la modificación legislativa como una ampliación del espectro indemnizatorio, abarcando tanto el ámbito contractual como legal. Pensar lo contrario presupone ir

15 De la Maza, Íńigo (2012) Consumidores: El suministro de información como técnica de protección de los consumidores: los deberes precontractuales de información. Santiago: Thomson Reuters, p. 224, "Existen supuestos en los cuales la finalidad de la imposición del deber de información no es prioritariamente la protección de la libertad contractual sino la protección del consumidor. La información no se orienta a la formación del consentimiento sino a la seguridad en el consumo".

16 De la Maza (2012) 222.

17 "Artículo 3․- Son derechos y deberes básicos del consumidor: e) El derecho a la reparación e indemnización adecuada y oportuna de todos los daños materiales y morales en caso de incumplimiento de cualquiera de las obligaciones contraídas por el proveedor, y el deber de accionar de acuerdo a los medios que la ley le franquea, (...)".

18 Historia de la Ley 19.955 modifica la Ley $\mathrm{N}^{\circ} 19.496$ sobre protección de los derechos de los consumidores, 14 de julio de 2004, p. 130. 
en contra del espíritu amplio y protector de la norma respecto de los consumidores.

\author{
Luego, en los artículos 19,20 y $21^{19}$ se consagra la denominada ga-
} rantía legal por productos y servicios, que implica dotar al consumidor en

19 "Artículo 19.- El consumidor tendrá derecho a la reposición del producto o, en su defecto, a optar por la bonificación de su valor en la compra de otro o por la devolución del precio que haya pagado en exceso, cuando la cantidad o el contenido neto de un producto sea inferior al indicado en el envase o empaque.

Artículo 20.- En los casos que a continuación se señalan, sin perjuicio de la indemnización por los dańos ocasionados, el consumidor podrá optar entre la reparación gratuita del bien o, previa restitución, su reposición o la devolución de la cantidad pagada:

a) Cuando los productos sujetos a normas de seguridad o calidad de cumplimiento obligatorio no cumplan las especificaciones correspondientes;

b) Cuando los materiales, partes, piezas, elementos, sustancias o ingredientes que constituyan o integren los productos no correspondan a las especificaciones que ostenten o a las menciones del rotulado;

c) Cuando cualquier producto, por deficiencias de fabricación, elaboración, materiales, partes, piezas, elementos, sustancias, ingredientes, estructura, calidad o condiciones sanitarias, en su caso, no sea enteramente apto para el uso o consumo al que está destinado o al que el proveedor hubiese señalado en su publicidad;

d) Cuando el proveedor y consumidor hubieren convenido que los productos objeto del contrato deban reunir determinadas especificaciones y esto no ocurra;

e) Cuando después de la primera vez de haberse hecho efectiva la garantía y prestado el servicio técnico correspondiente, subsistieren las deficiencias que hagan al bien inapto para el uso o consumo a que se refiere la letra c). Este derecho subsistirá para el evento de presentarse una deficiencia distinta a la que fue objeto del servicio técnico, o volviere a presentarse la misma, dentro de los plazos a que se refiere el artículo siguiente;

f) Cuando la cosa objeto del contrato tenga defectos o vicios ocultos que imposibiliten el uso a que habitualmente se destine;

g) Cuando la ley de los metales en los artículos de orfebrería, joyería y otros sea inferior a la que en ellos se indique.

Para los efectos del presente artículo se considerará que es un solo bien aquel que se ha vendido como un todo, aunque esté conformado por distintas unidades, partes, piezas o módulos, no obstante que estas puedan o no prestar una utilidad en forma independiente unas de otras. Sin perjuicio de ello, tratándose de su reposición, esta se podrá efectuar respecto de una unidad, parte, pieza o módulo, siempre que sea por otra igual a la que se restituye.

Artículo 21.- El ejercicio de los derechos que contemplan los artículos 19 y 20 deberá hacerse efectivo ante el vendedor dentro de los tres meses siguientes a la fecha en que se haya recibido el producto, siempre que este no se hubiere deteriorado por hecho imputable al consumidor. Si el producto se hubiere vendido con determinada garantía, prevalecerá el plazo por el cual esta se extendió, si fuere mayor.

El consumidor que, en el ejercicio de los derechos que contempla el artículo 20, opte por la reparación, podrá dirigirse, indistinta o conjuntamente, al vendedor, al fabricante o al importador. Hecha la opción, el requerido no podrá derivar el reclamo. Serán solidariamente responsables por los perjuicios ocasionados al consumidor, el proveedor que haya comercializado el bien o producto y el importador que lo haya vendido o suministrado.

En caso de que el consumidor solicite la reparación solo al vendedor, este gozará del derecho de resarcimiento señalado en el artículo 22 .

Las acciones a que se refiere el inciso primero podrán hacerse valer, asimismo, indistintamente en contra del fabricante o el importador, en caso de ausencia del vendedor por haber sido sometido a un procedimiento concursal de liquidación, término de giro u otra circunstancia semejante. Tratándose de la devolución de la cantidad pagada, la acción no podrá intentarse sino respecto del vendedor. 
casos de adquisición de productos con vicios cuantitativos o cualitativos de una serie de remedios de ejercicio alternativo. Estos son: la reparación gratuita del bien; la reposición del bien previa devolución de lo recibido; y la restitución de la cantidad pagada previa devolución del bien recibido. Lo anterior es sin detrimento de la acción de perjuicios, según prescribe expresamente el artículo 20, o bien, por remisión a la norma general contemplada en el artículo $3^{\circ}$ letra e) de la Ley.

De modo tangencial, variadas letras del artículo 17 como las E, I y $\mathrm{L}$ adicionan a la sanción de nulidad de las respectivas cláusulas abusivas, la indemnización de perjuicios que pudiere determinarse en favor del consumidor, acción reparadora que sigue los parámetros indicados en el artículo $3^{\circ}$ letra e), ya referido. En idéntica línea, el artículo 49 inserto en el párrafo $5^{\circ}$ del Título III, señala que el incumplimiento de las obligaciones prescritas en él quedará sujeto al pago de las indemnizaciones por los daños y perjuicios que se ocasionen.

Observada esta panorámica en la LDPC, encontramos una indemnización de perjuicios amplia y oportuna, cuyo fin es dejar indemne al consumidor que enfrentado a la necesidad de pretender adquirir, utilizar o

El vendedor, fabricante o importador, en su caso, deberá responder al ejercicio de los derechos a que se refieren los artículos 19 y 20 en el mismo local donde se efectuó la venta o en las oficinas o locales en que habitualmente atiende a sus clientes, no pudiendo condicionar el ejercicio de los referidos derechos a efectuarse en otros lugares o en condiciones menos cómodas para el consumidor que las que se le ofreció para efectuar la venta, salvo que este consienta en ello.

En el caso de productos perecibles o que por su naturaleza estén destinados a ser usados o consumidos en plazos breves, el término a que se refiere el inciso primero será el impreso en el producto o su envoltorio o, en su defecto, el término máximo de siete días.

El plazo que la póliza de garantía otorgada por el proveedor contemple y aquel a que se refiere el inciso primero de este artículo, se suspenderán durante el tiempo en que el bien esté siendo reparado en ejercicio de la garantía.

Tratándose de bienes amparados por una garantía otorgada por el proveedor, el consumidor, antes de ejercer alguno de los derechos que le confiere el artículo 20, deberá hacerla efectiva ante quien corresponda y agotar las posibilidades que ofrece, conforme a los términos de la póliza.

La póliza de garantía a que se refiere el inciso anterior producirá plena prueba si ha sido fechada y timbrada al momento de la entrega del bien. Igual efecto tendrá la referida póliza aunque no haya sido fechada ni timbrada al momento de la entrega del bien, siempre que se exhiba con la correspondiente factura o boleta de venta.

Tratándose de la devolución de la cantidad pagada, el plazo para ejercer la acción se contará desde la fecha de la correspondiente factura o boleta y no se suspenderá en caso alguno. Si tal devolución se acordare una vez expirado el plazo a que se refiere el artículo 70 del decreto Ley No 825, de 1974, el consumidor solo tendrá derecho a recuperar el precio neto del bien, excluidos los impuestos correspondientes.

Para ejercer estas acciones, el consumidor deberá acreditar el acto o contrato con la documentación respectiva, salvo en casos en que el proveedor tribute bajo el régimen de renta presunta, en los cuales el acto o contrato podrá ser acreditado mediante todos los medios de prueba que sean conducentes." 
disfrutar de un bien o servicio, resulta perjudicado. Dicho lo cual surgen las siguientes interrogantes: ¿qué debemos entender por este comportamiento?, ¿puede asimilarse dicha conducta en todos los casos a un contrato?, y ¿̇de qué indemnización se trata? ${ }^{20}$.

\section{2) EL ACTO DE ADQUIRIR, USAR O DISFRUTAR}

Cuando -según hemos afirmado en líneas que preceden- el legislador, los autores o inclusive los propios tribunales de justicia prescriben sobre la naturaleza del consumo, pareciese existir una confusión lingüística al hacer sinónimos aquel concepto con el contrato de consumo, en circunstancias que la realidad no parece estar pe se referida a este último, en razón de que estimamos que frente a este nuevo escenario comercial, se reglamentan intereses que van más allá de los de una relación contractual del derecho común. Ergo, pensamos que no se requiere como presupuesto, para los hechos materiales indicados, de la celebración de un contrato de consumo.

Entonces y con el objetivo de establecer el origen del régimen general de responsabilidad civil y la naturaleza de la acción indemnizatoria en el análisis de la LDPC perentorio es, entender previamente qué es el hecho de adquirir, utilizar o disfrutar; quiénes pueden verse involucrados; qué consecuencias desencadena; y de dónde emanan sus efectos.

Tanto el legislador como la doctrina han sido reacios a establecer una noción del hecho o acto del consumo, el que aparece innumerables veces citado por los legisladores al momento de discutir la LDPC y sus modificaciones, y por los autores que han escrito sobre la materia, sin embargo, no lo definen. Vemos dos intentos de Lara-Echaide y recientemente de Rodríguez ${ }^{21}$, en orden a establecer una diferencia respecto del

20 Véase VV. AA. (Pizarro Wilson, Carlos (1999) La protección de los consumidores en materia contractual. Santiago: Editorial Jurídica ConoSur; Corral Talciani, Hernán (2013) Lecciones de Responsabilidad Civil Extracontractual. Santiago: Editorial LegalPublishing, Segunda Edición; Pinochet (2007); Rodríguez (2014)).

21 "El acto de consumo es cualquier acto jurídico -título o negocio jurídico- que permite al consumidor o usuario entrar en posesión de un bien o disfrutar de un servicio, así como el acto material consistente en utilizar el bien o servicio objeto del contrato" (LARA GonZÁLEZ, Rafael et al. (2006) Consumo y derecho. Madrid: Editorial Esic, p. 25); el acto de consumo consiste en: "la adquisición de un bien o servicio determinado o del uso y goce del bien, a un sujeto llamado proveedor, por parte de otro sujeto, denominado consumidor, con el fin de obtener por parte de este último el provecho que se ofrece y que corresponde a la naturaleza de la especie o al ejercicio del derecho constituido a su respecto, todo ello en el marco de un mercado formal" (Rodríguez Grez, Pablo (2015) "¿Puede hablarse de un derecho del consumidor?”. Revista Actualidad Jurídica, $\mathrm{N}^{\circ} 31$, p. 69). 
contrato tratándolo como acto de consumo, pero terminan, en definitiva, circunscribiéndolo a un acto jurídico, en particular un contrato de consumo. Nuestra opinión difiere, pues se estima que el acto jurídico por el cual se adquiere, utiliza o disfruta de un determinado bien o servicio se convierte en un presupuesto del hecho de consumir, y por ello que difiere del contrato de consumo, aunque puede abarcarlo. El hecho del consumo resulta peculiar y difiere del contrato $^{22}$, ya que se trata de un estado o situación al que la ley regula y asigna efectos jurídicos ${ }^{23}$ y en donde el acto jurídico que le sirve de base no constituye la materia misma regulada, sino en cuanto presupuesto de operación o conditio iuris. Esto se aprecia particularmente para el caso de contravención a la LDPC, siendo quizás el de mayor importancia, el derecho a una indemnización amplia y oportuna en favor del consumidor. Así, en casos como el de Arias con So$\operatorname{dimac}^{24}$, una persona sin haber adquirido siquiera un bien del proveedor resultó dañada por un desperfecto del bien exhibido, siendo en definitiva protegida por la LDPC no por estar en presencia de un contrato de consumo sino por ser su comportamiento -de parte de quien está revisando o mirando el bien ofrecido- el hecho mismo del consumo. La Corte de Apelaciones de Concepción en dicho caso, razona indicando que: el derecho del consumo no tiene como único fundamento la existencia de un vinculo jurídico previo, ya que existen numerosas reglas que no tienen como supuesto la existencia de un contrato, como por ejemplo los artículos 13 y 15 de la Ley,

22 "La noción de consumidor se relaciona con un hecho jurídico, que es el 'consumir', y no específicamente con la calidad de acreedor o deudor de una obligación o con un contrato en particular" (Lorenzzetti, Ricardo (2004) Tratado de los contratos, parte general, tomo I. Buenos Aires: Editorial Rubinzal y Culzoni, p. 138).

23 "Aunque sigue sin adoptarse expresamente un criterio objetivo con el del «acto de consumo", reclamado por cierta doctrina, es cierto que con el término «actuar» del art. 3 TR-LGDCU (que sigue centrándose en un parámetro subjetivo negativo) y con la nueva mención de "intervenir en las relaciones de consumo» de la EM del TR-LGDCU, esa noción cuenta con un mayor anclaje en el Derecho positivo vigente. El camino hacia la objetivización también continúa con la elección del término actuar «en un ámbito» ajeno a una actividad profesional, en lugar de "con un propósito" o "con fines» ajenos a dicha actividad como en cambio señalan las Directivas de referencia. Sin duda, en esta actuación del consumidor caben todas las actividades antes verbalizadas por el art. 1 LGDCU como «adquirir, utilizar o disfrutar», por las que el consumidor o usuario entre en contacto con el bien o servicio por cualquier título; comprenderá actos jurídicos y actos materiales (consumidor jurídico/material), «relaciones de consumo» contractuales y extracontractuales, etc. Además, el amplio verbo ahora empleado apela a que un consumidor, más que ser, actúa como tal en concretas relaciones de consumo (supra, 2.1)". (CÁmara Lapuente, Sergio (2011) Comentarios a las normas de protección de los consumidores. Madrid: Colex, p. 133).

24 Corte de Apelaciones de Concepción. 24 de diciembre de 2007. Rol 174-2005. "Arias con Sodimac". Disponible en: http://corte.poderjudicial.cl/SITCORTEPORWEB/ DownloadFile.do?TIP_Documento=3\&TIP_Archivo=3\&COD_Opcion $=1 \&$ COD_ Corte=46\&CRR_IdTramite=3817592\&CRR_IdDocumento=3093484 [fecha de visita 21 de junio de 2016] p. 6. 
los cuales imponen obligaciones al proveedor respecto del consumidor no contratante.

Pensamos inclusive, y para los fines perseguidos por la LDPC, que en actos cotidianos como adquirir alimentos en un supermercado no presuponen necesariamente por el legislador la existencia del consentimiento exento de vicios, la presencia de objeto y causa lícita, etc.; pues, en este caso, el fin que se propone es resguardar una situación fáctica de perjuicio a quien consume o está en vías de hacerlo; luego el acto es solo un presupuesto para la regulación. La sencilla conducta de pasar un producto por caja queda amparada por la LDPC no por ser ella, necesariamente, un contrato de compraventa, sino en razón de ser un hecho relevante de consumo, que debe protegerse. Lo mismo para el caso de aquel sujeto que ingresó al supermercado o centro comercial y estacionó su vehículo, y luego tras minutos, a su regreso, este ya no está por haber sido robado. E inclusive lo pensamos también para hechos que se generan a propósito de una compraventa producto de ofertas que realiza el proveedor como sucedería para aquel consumidor que compró una vivienda con dos circuitos de calefacción según planos entregados, y luego de habitada se advierte que la casa presenta uno solo; o en el mismo caso, cuando las áreas verdes que se explicitan como parte de la oferta en folletos o páginas web del proveedor difieren de lo que efectivamente entrega aquel a los consumidores.

De esta manera estimamos que el consumo es una realidad jurídica que se asimila estrictamente a un hecho y su presupuesto, el acto jurídico en el que reposa, es un elemento propio del tipo para calificar como regla a la persona del consumidor, pero no es la materia misma regulada.

En sentido amplio, hecho jurídico es cualquier evento al cual la norma ligue la formación, modificación o extinción de consecuencias jurídicas ${ }^{25}$, o bien, como opina Ducci ${ }^{26}$, son hechos humanos voluntarios a los que la ley atribuye un efecto jurídico no querido o distinto del perseguido por su autor. En palabras de Montiel ${ }^{27}$, son necesarios para la producción de efectos jurídicos tanto el hecho como el precepto que lo consagra, el hecho por sí mismo carece de valor jurídico por lo que necesita de la norma para cobrar ese valor y será jurídico en la medida que una norma de derecho le asigne efectos normativos. En esta línea, por

25 Barasi, Lodovico (1955) Instituciones de derecho civil. Trad. Haro y Faleón. T.I. Barcelona: Editorial Bosch, p. 151.

26 Ducci Claro, Carlos (1995) Derecho Civil, Parte General. 4a Edición. Santiago: Editorial Jurídica de Chile, p. 235.

27 Montiel Gómez, Adolfo (1966) El hecho jurídico. Santiago: Imprenta Editorial El Sur, p. 36. 
ejemplo, si una persona al ingresar a un establecimiento comercial y antes siquiera de transar la adquisición de un bien o la prestación de un servicio sufre daños producto de la manipulación de un bien que exhibe a la venta el proveedor, será un hecho que cambiará la realidad preexistente, pues está dotado de relevancia jurídica para la LDPC, toda vez que se crea una situación que modifica el curso normal de las cosas entre quien sufrió el daño y el proveedor ${ }^{28}$. Esto fue lo que sucedió en el citado caso Arias con Sodimac.

Imperioso resulta entonces establecer a quiénes involucra esta realidad jurídica denominada consumo.

Conforme al artículo $1^{\circ}$ de la $\mathrm{LDPC}^{29}$, son el proveedor y el consumidor. Del tenor literal de la definición legal, solo serían normados, en el caso de los consumidores el denominado consumidor jurídico, es decir, la persona que ejecuta un acto jurídico oneroso de aquellos que la ley prevé. Sin embargo, nuestra jurisprudencia y doctrina nacional ${ }^{30}$ han ampliado el concepto al consumidor material (quien lo utiliza o disfruta) en el evento de que ambas calidades no coincidan y, por lo tanto, quede desprotegido legalmente este último. En este sentido, el elemento oneroso deja de ser imprescindible para resguardar al consumidor, amparándose de igual manera un acto jurídico gratuito ${ }^{31}$.

Al postular que lo importante -en esta situación de querer adquirir usar y disfrutar- para la LDPC es el consumo y no el contrato debemos hacernos cargo de cómo entonces la Ley es aplicable a personas no contratantes, sujetos que en ocasiones siquiera han interactuado directamente

28 Vial del Río, Víctor (2003) Teoría general del acto jurídico. Santiago: Editorial Jurídica de Chile, p. 12.

29 "Artículo $1^{\mathrm{o}}$.- La presente ley tiene por objeto normar las relaciones entre proveedores y consumidores, establecer las infracciones en perjuicio del consumidor y señalar el procedimiento aplicable en estas materias.

Para los efectos de esta ley se entenderá por:

1.- Consumidores o usuarios: las personas naturales o jurídicas que, en virtud de cualquier acto jurídico oneroso, adquieren, utilizan, o disfrutan, como destinatarios finales, bienes o servicios. En ningún caso podrán ser considerados consumidores los que de acuerdo al número siguiente deban entenderse como proveedores.

2.- Proveedores: las personas naturales o jurídicas, de carácter público o privado, que habitualmente desarrollen actividades de producción, fabricación, importación, construcción, distribución o comercialización de bienes o de prestación de servicios a consumidores, por las que se cobre precio o tarifa.

No se considerará proveedores a las personas que posean un título profesional y ejerzan su actividad en forma independiente."

Barrientos Camus, Francisca (2011) "Derecho de consumo, comentarios de jurisprudencia". Revista Chilena de Derecho Privado, No 16, p. 363.

31 Fernández Fredes, Francisco (2003) Manual de derecho chileno de protección al consumidor. Santiago: LexisNexis, pp. 110-111. 
con el vendedor. Siguiendo a Echialde-Lara ${ }^{32}$, cuando al consumidor se le reconoce la protección y el ejercicio de los derechos sin haber contratado, nos encontramos ante el denominado consumidor material.

Si bien todos en algún momento tenemos la calidad de consumidor no se trata de un estado permanente, nacerá aquel solo cuando seamos objetivamente presupuesto de protección por la normativa que regula el consumo. Si permanecemos esclavos a lo prescrito en la definición legal sin hacernos cargo de una análisis sistemático del conjunto de la Ley, obviando principios fundamentales como la confianza impresa por el proveedor en su oferta a persona indeterminada y el derecho a la seguridad que tiene el consumidor expresamente establecido en la Ley, llegaremos al absurdo de que una persona por el solo hecho de no comprar un bien o servicio, estará desprotegida por la Ley $\mathrm{N}^{\circ} 19.496$, lo que resulta una injustificada restricción ${ }^{33}$. Entonces, la citada norma de la LDPC que define al consumidor contratante hay que complementarla necesariamente con los principios inspiradores de la propia Ley, en particular transparencia, confianza y protección de la parte débil en el consumo (seguridad), ellos nos lleva a la inevitable afirmación de que en el acto del consumo merece protección todo aquel sujeto que está expuesto a la situación de consumir, por ejemplo, quien recibe un regalo, la persona que circula por un centro comercial, etc.

Más allá de los términos que empleó el legislador al definir al consumidor en el artículo $1^{\circ}$ de la Ley, aquella calificación debe ser atribuida a quien actúa de determinada manera y con relación exclusiva a esa actuación - pretender adquirir, usar o disfrutar-. Momberg ${ }^{34}$ hace una clara distinción entre lo prescrito por el artículo $1^{\circ}$ y el análisis sistemático de las demás disposiciones de la LDPC, afirmando que la definición de consumidor admite que se trate no solo de personas ligadas por vínculos contractuales -actos jurídicos onerosos-, debiendo incluirse a todo acto susceptible de producir efectos jurídicos, siendo para el referido autor importante la norma del inciso primero del artículo $1^{\circ}$ en cuanto dispone en términos muy amplios que "La presente ley tiene por objeto normar las relaciones entre proveedores y consumidores". Compartimos el alcance

\footnotetext{
32 LaRa-Echaide (2006) 42.

33 Corte de Apelaciones de Santiago. 5 de enero de 2008. Rol: 9663-2008. "Cabello con Hipermercado Alameda". Disponible en: http://corte.poderjudicial.cl/ SITCORTEPORWEB/DownloadFile.do?TIP_Documento=3\&TIP_Archivo=3\&COD_ Opcion $=1 \& C O D \_C o r t e=90 \& C R R \_I d T r a m i t e=1065445 \& C R R \_I d D$ Documento $=972900$ [fecha de visita 21 de junio de 2016] p. 4.

34 Momberg Uribe, Rodrigo (2013) La Protección de los derechos de los consumidores, comentario articulo $1^{\circ}$. Santiago: Thomson Reuters, p. 6.
} 
de Momberg, con la salvedad que el espectro del consumidor es más amplio -teniendo en cuenta los principios enunciados de la Ley- respecto de quien ejecuta un acto, pues estimamos que abarca a cualquier hecho de consumo susceptible de producir consecuencias jurídicas.

Por ello, y con el fin último de reflejar justificadamente una protección amplia, debemos tener presente al referirnos al consumidor no contratante, normas como la del artículo $3^{\circ}$ de la LDPC, en cuanto prescribe, entre otros, el deber del proveedor de no discriminar arbitrariamente o el deber de evitar riesgos que puedan afectar la seguridad del consumidor; el artículo 12, en cuanto se obliga al proveedor a respetar los términos, condiciones o modalidades conforme se hubiere ofrecido la entrega de un bien o la prestación de un servicio; y también aparece patente del artículo 15 , en cuanto debe el proveedor respetar la dignidad y derecho de las personas con ocasión de los sistemas de vigilancia y seguridad que mantenga en su establecimiento comercial. Todas ellas, y solo con afán ilustrativo, permiten demostrar que la LDPC protege al consumidor en un sentido amplio, esto es, quien se expone al hecho de consumir y no solo el consumidor que ejecuta un acto jurídico oneroso, como erradamente pensamos han sustentado Jara y Pinochet ${ }^{35}$ para el caso que estudiamos. Situación distinta dentro de la misma Ley es la que ocurre con las cláusulas abusivas o a propósito de las demandas colectivas en que imperioso es para la Ley la existencia de un contrato, pero este, estimamos, constituye una regulación en específico y como tal, apartada del sistema general de responsabilidad que mediante esta investigación fundamos por lo que no nos detendremos en su análisis.

En legislación comparada existe una tendencia cada vez más marcada en esta misma línea. A modo ejemplar, en el derecho español ${ }^{36}$, a propósito del artículo 3 del Real Decreto Legislativo 1/ 2007, se define al consumidor o usuario como "las personas físicas o jurídicas que actúan en un ámbito ajeno a una actividad empresarial o profesional". Igualmente,

35 Véase VV. AA. (Jara Amigo, Rony (1999) Ámbito de Aplicación de la Ley Chilena de Protección al Consumidor: Inclusiones y Exclusiones. Santiago: Cuadernos de Extensión Jurídica, Universidad de los Andes; Pinochet (2007).

36 Cámara Lapuente en cuanto a la dicotomía que existía en el artículo 1 de la Ley General para la Defensa de los Consumidores y Usuarios expresa que: "Lo cierto es que esa dicotomía tenía lugar en el propio tenor literal del artículo 1 LGDCU, que aludía a las personas "que adquieran, utilizan o disfrutan como destinatarios finales» y no parece que la nueva dicción del artículo 3 TR-LGDCU haya alterado la posibilidad de entender protegido al puro consumidor material (no contratante) en ciertos aspectos, dada la amplitud del verbo «actuar» que ahora se contempla y que permite cubrir no solo relaciones contractuales, sino cualquier acto de consumo comprendido en los tres verbos anteriormente utilizados" (CÁMara Lapuente (2011) 113). 
aparece de manifiesto en la reforma integral a la Ley de Defensa de los Consumidores de Argentina del año $2008^{37}$, en que se modificó el concepto de consumidor estableciendo, para definirlo, como: "toda persona física o jurídica que adquiere o utiliza bienes o servicios en forma gratuita u onerosa como destinatario final, en beneficio propio o de su grupo familiar o social" y quien "sin ser parte de una relación de consumo, como consecuencia o con ocasión de ella adquiere o utiliza bienes o servicios como destinatario final o de grupo familiar o social, y a quien de cualquier manera está expuesto a una relación de consumo”.

Por otro lado, como partícipe está la figura del proveedor, que también puede abarcar a más de un sujeto, toda vez que se trata de un concepto amplio que incluye tanto a las personas naturales como jurídicas, comprendiendo las diversas actividades ${ }^{38}$ que pueda desarrollar en la cadena de puesta en marcha de un producto en el mercado (producción, fabricación, importación, construcción, distribución o comercialización de bienes o de prestación de servicios). En este aspecto la LDPC va más allá de la bilateralidad de los contratos ${ }^{39}$, con lo que ya se vislumbra una diferencia con el derecho común respecto de una relación contractual típica, en razón de que, verbigracia, podrán ser responsables fabricante, importador y vendedor en el caso del artículo 21 de la referida ley, siendo solo este último "la parte" en un contrato típico de compraventa.

Ley $\mathrm{N}^{\circ} 24.240$ de 1993.

38 "Para efectos particulares, en algunos casos la Ley amplía el concepto de proveedor, incluyendo a operadores mediatos respecto del consumidor. Así ocurre en el caso del artículo 21, incluido en el Párrafo $5^{\circ}$ del Título II, sobre Responsabilidad por Incumplimiento, en virtud del cual en caso que el consumidor opte por la reparación del bien, puede dirigirse indistinta o conjuntamente al vendedor, al fabricante o al importador. El mismo artículo señala que respecto de la indemnización de perjuicios, son solidariamente responsables el proveedor que haya comercializado el bien o producto y el importador que lo haya vendido o suministrado. Por último, en caso que el consumidor opte por la restitución del bien, podrá dirigirse indistintamente, en caso de ausencia del vendedor, contra el fabricante o el importador" (MOMBERG URiBE, Rodrigo (2004) "Ámbito de aplicación de la ley Nº 19.496 sobre protección de los derechos de los consumidores". Revista de Derecho de la Universidad Austral de Chile, Vol. XVII, pp. 41-62).

39 "Bajo el artículo 23 de la LPDC también se puede perseguir la responsabilidad del fabricante, sea que venda o no sus productos directamente al público consumidor. En el caso del fabricante-no vendedor, la responsabilidad estaría unida a la del vendedor. Para perseguir la responsabilidad del fabricante no vendedor, por los límites del artículo 23 de la LPDC, la víctima debe dirigir su acción juntamente contra el vendedor y el fabricante. No cabría la interposición de una acción directa contra el fabricante." (BARRIENTOS CAMUS, Francisca (2010) "La responsabilidad del fabricante bajo el artículo 23 de la ley de protección de los derechos de los consumidores y su relación con la responsabilidad civil del vendedor". Revista Chilena de Derecho Privado, N 14, p. 45). 
Es dable destacar que, como ocurre en Argentina ${ }^{40}$, quedan excluidas del concepto de proveedor las profesiones liberales. Distinto es el caso de la legislación de los países de la Comunidad Europea, como Espańa, que optan por un concepto amplio, extendiendo inclusive el término a empresario ${ }^{41}$; así el artículo 4 del Real Decreto 1/2007 dispone que: "se considera empresario a toda persona física o jurídica que actúa en el marco de su actividad empresarial o profesional, ya sea pública o privada”.

Dicho esto podemos conceptualizar el hecho del consumo como: aquel hecho jurídico consistente en el evento cierto o potencial de consumir, el que se presenta por mandato legal cuando el consumidor ingresa a la esfera física del proveedor con el fin de adquirir, utilizar o disfrutar un producto o servicio ofrecido, o bien, respecto de quien de cualquier forma, está expuesto a la situación de consumir.

En este escenario, se comprende y advierte la peculiaridad que existe frente a normas contractuales del derecho civil. Reiteramos así la idea de que con ocasión del hecho del consumo podrá generarse responsabilidad, que implique en último término dotar al consumidor en su sentido amplio, de una acción indemnizatoria amplia y omnicomprensiva de sus intereses lesionados.

\section{3) FUENTE DE LA RESPONSABILIDAD EN EL CONSUMO}

Para resolver la cuestión, esto es, comprender el régimen de responsabilidad aplicable al proveedor es necesario remontarnos a las obligaciones ${ }^{42}$, ya que la responsabilidad de aquel surge recién como una consecuencia frente al incumplimiento de aquellas, entendida como la falta de satisfacción íntegra y oportuna de la obligación de lo por ella prescrita. Por lo anterior, primordial es conocer cuál es la fuente de las obligaciones a propósito del hecho del consumo ${ }^{43}$, teniendo a la vista las

$40 \quad$ Ley $\mathrm{N}^{\circ} 24.240$ de 1993.

41 "(...) tras analizar las diferentes actividades que pueden ser objeto de las relaciones de consumo, se puede concluir que el término empresario utilizado por la normativa sobre protección de los consumidores incluye todo tipo de empresario, sin limitarse solamente a empresarios mercantiles". (Botana García, Gema y Llamas Pombo, Eugenio (2005) Ley para la defensa de los consumidores y usuarios. Madrid: La Ley, p. 81).

42 Meza Barros, Ramón (1997) Manual de derecho civil, de las obligaciones. Santiago: Editorial Jurídica de Chile, p. 11. "La obligación es un vínculo jurídico entre personas determinadas, en cuya virtud una se encuentra para con la otra en la necesidad de dar, hacer o no hacer una cosa".

43 Sobre el particular véase Rodríguez (2014) 207; Pinochet (2007) 17; Guerrero Becar, José Luis (2008) La distinción entre contravención infraccional e incumplimiento contractual o contravención civil en materia de protección de derechos del consumidor. Valparaíso: Ediciones 
clásicas -contrato, delito, cuasicontrato, cuasidelito y ley- reconocidas en nuestro derecho común a propósito del artículo 1437 del Código Civil y que la tendencia actual clasifica o estudia desde la perspectiva del contrato, del delito o del cuasidelito civil. Sobre el punto y siguiendo a Abeliuk y Meza Barros ${ }^{44}$ la enumeración de las fuentes de las obligaciones clásicas acogidas por el Código Civil chileno es taxativa, de manera que cualquier figura jurídica que las genere hay que encuadrarla forzadamente en alguna de dichas categorías.

En la LDPC observamos que la autonomía privada que conocemos como formadora del consentimiento en materia contractual es irrelevante desde el punto de vista de lo que une a las partes y de las normas que reglamentan el hecho del consumo.

Situaciones como el ingreso de una persona a un centro comercial al margen de comprar un bien o servicio merece amparo, según señala la LDPC. Luego concluimos que la ley frente a ese hecho jurídico -el consumo- liga la formación de una consecuencia jurídica de amparo ya que si los derechos del consumidor llegasen a ser vulnerados por el proveedor será este responsable.

Por lo anterior, y para un cabal entendimiento, creemos necesario desfragmentar los elementos tradicionales que concurren en la responsabilidad civil con el fin último de establecer qué naturaleza jurídica tiene esta en la LDPC.

\section{(3.1.) SUJETOS INTERVINIENTES}

Reiteramos la idea de que a diferencia de lo que ocurre en un contrato de compraventa tradicional ${ }^{45}$, en el hecho del consumo pueden ser

Universitarias de Valparaíso, p. 448; y Contardo, Juan Ignacio (2013) La Protección de los derechos de los consumidores, comentario artículo $3^{\circ}$ letra e. Santiago: Thomson Reuters, p. 123.

$44 \quad$ Véase VV.AA. Abeliuk (2008) 53; Meza Barros (1997) 10.

45 "Así las cosas, no resulta sustentable exigir la celebración de negocio jurídico alguno para ser considerado consumidor, puesto que es la propia ley la que establece infracciones y derechos cuando ello no ha ocurrido". "Por otra parte, se debe recordar que tanto el consumidor concreto como el abstracto gozan de tutela jurídica, aunque de manera diversa. En efecto, el primero de ellos corresponde al sujeto que efectivamente ha celebrado un contrato con el proveedor, y quien es titular de «derechos que puedan ejercitar individualmente en su interés particular», tales como la garantía legal, el cumplimiento forzado, resolución, etc. Por su parte, el consumidor abstracto o en sentido amplio hace alusión «a todos los ciudadanos en cuanto personas que aspiran a tener una adecuada calidad de vida", concepto que permite atribuir derechos a la comunidad en general, como potenciales consumidores. A ellos se les reconocen ciertas garantías generales o básicas, y que en nuestra Ley se encuentran consagra- 
partícipes personas que nunca concurrieron con su voluntad o consentimiento a dar vida al hecho, toda vez que se está en presencia de un hecho jurídico al que la ley asigna efectos o consecuencias jurídicas. Entonces, en una primera línea son partícipes en el hecho del consumo proveedor y consumidor jurídico, como sucede en el caso de quien ingresa a un supermercado y adquiere en aquel diferentes productos que allí se expenden. En segundo lugar, y atendida la normativa protectora de la ley, analizada en forma sistemática como se justificó antes, es objeto de protección además el consumidor material (que lo utiliza o disfruta). A modo comparativo en este sentido, más claro y razonable en su alcance es la regla del artículo 17 del Código del Consumidor de Brasil, que dispone que en caso de daños causados por productos defectuosos se equiparan a los consumidores todas las víctimas del evento. En tercer lugar, por parte del proveedor puede ser responsable el importador y fabricante como sucede en el caso de los artículos 21 y 47 de la LDPC, para las hipótesis de productos defectuosos y peligrosos, respectivamente.

\section{(3.2.) INEXISTENCIA DE UN FACTOR SUBJETIVO DE IMPUTACIÓN}

La imputación en la responsabilidad consistirá en el elemento que la ley prevé para atribuir jurídicamente la obligación de indemnizar un daño, es contestar al por qué se responde, que en el caso de la responsabilidad extracontractual será dolo o culpa. El objetivo de la LDPC es resguardar los intereses del consumidor, de suerte que aquel quede en un plano de igualdad frente al proveedor producto del alto nivel de asimetría informativa que existe en un mercado de ventas en masas. Por tal razón el interés de la Ley está puesto en el perjudicado y no en el autor del daño, con lo que se rehúye del establecimiento de un presupuesto subjetivo ${ }^{46}$,

das en su Art. 3, entre las cuales encontramos al derecho a la información (artículo 3 letra b), a la educación (artículo 3 letra f), a la seguridad en el consumo, a la protección de la salud y el medio ambiente." (Isler Soto, Erika (2014) "Comentario de sentencia sobre el concepto de consumidor". Revista Chilena de Derecho y Ciencia Política, p. 157).

46 Coincidimos con Corral cuando afirma que: "el juicio objetivo de contrariedad de la conducta con específicos deberes de cuidados emanados de fuente legal o con principios y valores constitutivos del ordenamiento jurídico, es una exigencia autónoma e independiente de la culpabilidad: dolo o culpa, y del dańo. Es cierto que muchas veces van relacionados, pero no siempre es así: puede haber culpa, pero no ilícito y un daño puede causarse de manera justificada. Incluso debe sostenerse que el elemento de la antijuridicidad o contrariedad del comportamiento de derecho es exigido tratándose de responsabilidad por riesgo u objetiva, ya que para que esta surja debe existir alguna conducta -activa u omisiva- transgresora al menos de un deber genérico de garantizar seguridad a las eventuales víctimas" (CORRAL (2013) 118). 
que de estar, entorpecería el actuar del lesionado al tener una mayor carga en juicio.

Resulta entonces interesante analizar el incumplimiento desde el punto de vista objetivo de la insatisfacción del acreedor, en lugar de la valoración del deudor. Sobre el punto, Barrientos opina que no hay que cimentar las bases de la responsabilidad en atención a la conducta del proveedor deudor, sino que al resultado esperado por el consumidor ${ }^{47}$. En razón de lo cual la LDPC obliga al proveedor a: i) reparar e indemnizar al consumidor adecuada y oportunamente todos los daños materiales y morales que se produzcan con ocasión del consumo; y ii) respetar los términos, condiciones y modalidades conforme a las cuales se hubiere "ofrecido" o "convenido" con el consumidor la entrega de un bien o la prestación del servicio.

Así las cosas, se observa, salvo la norma de los artículos 23, 28, 45 y 47 la inexistencia de un factor subjetivo de imputación de responsabilidad. La Ley es quien prescribe el estándar mínimo que el proveedor ha de respetar en el mercado, añadiendo que la sola contravención de las obligaciones legales lo hará responsable para con el consumidor, debiendo reparar o indemnizar, según si ha existido daño y si este se ha producido en el bien o servicio adquirido o en la integridad física o psíquica del consumidor. Siguiendo a Yuseff ${ }^{48}$, la responsabilidad civil debe propender a asegurar a las víctimas la indemnización de los daños que hayan sufrido. Por su parte Contardo ${ }^{49}$, a propósito de la reparación adecuada de los perjuicios que sufra el consumidor, indica que la limitación estará dada por las reglas de causalidad objetivamente consideradas y no por el grado de culpa del proveedor.

\section{(3.3.) EXTENSIÓN DE LOS DAÑOS}

El derecho se presenta al hombre como una reacción frente al perjuicio sufrido por un sujeto. El daño ${ }^{50}$ que prescribe la LDPC como repa-

47 BarRientos (2014) 66.

48 Yuseff, Gonzalo (2000) Responsabilidad civil y responsabilidad objetiva. Santiago: La Ley, p. 193.

49 Contardo (2013) 127.

50 “(..) daño es todo detrimento, perjuicio menoscabo, dolor o molestia que sufre un individuo en su persona, bienes, libertad, honor, crédito, afectos, creencias, etc. El daño supone la destrucción o disminución por insignificante que sea, de toda ventaja o beneficio patrimonial o extrapatrimonial de que goza un individuo. Su cuantía y la mayor o menor dificultad para acreditarlo y apreciarlo son indiferentes; la ley no las considera". (Alessandri (1983) 210); "el daño implica la privación de algún bien, de un derecho o la alteración de alguna 
rable es amplio y comprenderá tanto a la persona del consumidor como al bien o servicio adquirido. El tantas veces citado artículo $3^{\circ}$ letra e) da cuenta de dos derechos a favor del consumidor, es así como establece el derecho a la "reparación" e "indemnización" adecuada y oportuna de todos los daños materiales y morales en caso de incumplimiento de cualquiera de las obligaciones contraídas por el proveedor ${ }^{51}$. En los artículos $19^{\circ}$ y $20^{\circ}$ se establece la garantía legal a favor de los consumidores "con ocasión” de los daños sufridos en la adquisición de un bien o en la ejecución de un servicio por parte del proveedor. Por su parte, el artículo 47 permite el ejercicio de una acción indemnizatoria contra productor, importador y primer distribuidor o prestador del servicio, en su caso, para el evento de daños en las personas a raíz de la peligrosidad de un producto o servicio, o atendida su toxicidad en niveles considerados como nocivos para la salud o la seguridad de las personas.

Sobre el punto, Contardo ${ }^{52}$ diferencia reparación de indemnización, otorgando a esta última su sentido tradicional de resarcimiento de dańos, pero respecto del concepto reparación agrupa a todos aquellos remedios distintos de la indemnización de perjuicios, como la garantía legal de los artículos 20, 21 y 41, la suspensión o corrección de la publicidad, el cambio de mercancía peligrosa por otra análoga y de valor equivalente y la nulidad del contrato por incluir cláusulas abusivas.

Dicho esto nos parece propicio distinguir entre daños en los bienes o servicios adquiridos y daños en la persona del consumidor con ocasión del hecho de consumir.

\section{(3.3.1.) Daños en los bienes y servicios}

A propósito de la adquisición de un bien o servicio por el consumidor, la LDPC establece a favor de este una garantía legal en los artículos $19^{\circ}$ y $20^{\circ}$ que consistirá en el ejercicio de derechos alternativos: reparación, reposición, rebaja de precio y resolución, adicional a ellos está la indemnización por los daños ocasionados. Se puede concebir este deber

situación jurídica o lesión de un interés, presente o futuro”. (Domínguez Águila, Ramón (1990) "Consideraciones en torno al daño en la responsabilidad civil. Una visión comparatista". Revista de Derecho Universidad de Concepción, $\mathrm{N}^{\circ} 188$, p. 125).

51 En Argentina con la incorporación del artículo 40 bis por Ley 26.361 se establece el daño directo es "todo perjuicio o menoscabo al derecho del usuario o consumidor, susceptible de apreciación pecuniaria, ocasionando de manera inmediata sobre sus bienes o sobre su persona, como consecuencia de la acción u omisión del proveedor de bienes o del prestador de servicios".

52 Contardo (2013) 122. 
especial del proveedor, en palabras de Barrientos $^{53}$, diverso del reglamentado en el Código Civil a propósito del saneamiento de los vicios redhibitorios. No profundizaremos sobre este punto por estar ya bastante estudiado, solo nos parece dejar en claro que se trata de un sistema de remedios no contemplados como tal en el derecho común y, en tal sentido, lo diferencian y particularizan a propósito del derecho del consumo. Además, destacamos la idea de que la referida garantía tiene un plazo de ejercicio de tres meses, al cabo de los cuales estimamos que si bien el consumidor pierde el ejercicio alternativo que la Ley le confiere, mantiene vigencia la acción de perjuicios conforme al artículo $3^{\circ}$ letra e) de la LDPC.

\section{(3.3.2.) Daños en el consumidor}

En el marco del consumo antes, durante o con posterioridad a la adquisición de un bien o a la prestación de un servicio, el consumidor puede verse expuesto a lesiones físicas o psíquicas por diversos factores. Este daño que la LDPC procura reparar resulta ser amplio pues se indemnizará no solo los daños materiales sino que también los morales. Se busca dejar indemne al consumidor, en el mismo estado que se encontraba antes de ser víctima del acto perjudicial que la Ley prescribe ${ }^{54}$.

Creemos entonces que en la LDPC y a propósito del hecho del consumo que es objeto de este estudio se trata de cubrir la totalidad de los perjuicios que experimentó el consumidor a consecuencia de la adquisición, use o disfrute del bien o servicio. Se observa con ello una diferencia de texto con la responsabilidad contractual que solo hace años atrás producto del trabajo doctrinal y jurisprudencial abarca los daños materiales y morales, pues siguiendo a letra al código de antiguo aquella quedaba limitada solo a daños materiales cuando nuestros tribunales superiores de justicia fallaban el caso, con lo que se vislumbra lo peculiar del sistema resarcitorio en la LDPC, que, en este punto, más bien presenta similitud con el sistema extracontractual como opina Baraona ${ }^{55}$. Barrientos, por su

53 Barrientos (2014) 58.

54 En palabras de De Cupis "no menor importancia reviste el establecer la magnitud, o sea, la dimensión o montante, el quantum del daño al que el ordenamiento jurídico atribuye valor de hecho jurídico, uniéndole una reacción propia". Agrega luego que "de poco serviría tener derecho al resarcimiento si fuera mínima la entidad del daño a resarcir. En consecuencia, importa enormemente precisar los límites cuantitativos dentro de los que el daño asume sentido jurídico". (De Cupis, Adriano (1970) El daño. Teoría general de la responsabilidad civil. Barcelona: Casa Editorial, pp. 245-246). 
parte, en relación al daño moral, estima que debería hablarse de daño no patrimonial, por ser esta expresión aún más amplia ${ }^{56}$.

Por cierto que el daño que experimente en el consumidor deberá ser probado según las normas generales. Habrá de demostrarse el efectivo perjuicio sufrido a su integridad física o psíquica $^{57}$, recién ahí nacerá el derecho indemnizatorio.

\section{(3.4.) Causalidad}

Si bien es el actuar del proveedor que al incumplir una norma legal podrá ocasionar daños al consumidor, no existe un factor psicológico -salvo las normas citadas, a saber: artículos 23, 28, 45 y 47- que opere de nexo con el daño. Se tratará, entonces, de una conexión normativa, ya que es la ley infraccionada la que deberá unirse al elemento dańoso y configurar la responsabilidad del vendedor, proveedor o fabricante y generar, en consecuencia, la reparación e indemnización amplia a favor del consumidor ${ }^{58}$. Sin dudas, el daño será efecto de la conducta del proveedor, pero antes de eso, es la LDPC la que se quebranta por lo que no resulta necesario indagar nuevos factores de imputación, en opinión de Baraona ${ }^{59}$, pues basta esa culpa infraccional que se entiende implícita

56 En igual sentido Isler "No obstante hubiese resultado técnicamente más deseable que el legislador utilizara la expresión "extrapatrimonial», con el objeto de comprender la indemnización de todos los perjuicios que pudieran generarse y no solo del pretium doloris, tal como ocurre con el Art. 6 de la ley uruguaya (Ley 17.250), aunque se entiende que su intención fue establecer la reparación íntegra de los daños causados” (IsLer (2014) 161).

57 En cuanto al daño moral "Si bien es cierto que no se puede exigir a la víctima prueba exacta del monto del perjuicio porque ello sería equivalente a negarle la indemnización, sí se le debe exigir que aporte los antecedentes a partir de los cuales se pueda extraer ese quantum". (Domínguez, Carmen (2006) "El daño moral en Chile: contornos y problemas". Anales de Derecho Pontificia Universidad Católica de Chile, $\mathrm{N}^{\circ} 1$, p. 327).

58 Opina Prevot sobre el punto que "Sabido es que, pues, en la primera categoría (responsabilidad objetiva), la noción de causa jurídicamente relevante pierde parte de su significado tradicional y cobra un especial relieve o, lo que es igual, adquiere una "configuración diferente". Dicho de otra forma, varía el "asiento" sobre el cual se edifica la indagación retrospectiva, ya que en un sistema objetivo de responsabilidad, la imputación del daño al agente se desvincula de todo ropaje de subjetividad y cabe atribuirlo al responsable, no porque se haya conducido en forma negligente, sino porque el resultado del hecho dańoso sobreviene a consecuencia de un evento ocurrido en el ámbito de aplicación de una norma especial." (Prevot, Juan Manuel (2010) "El problema de la relación de causalidad en el derecho de la responsabilidad civil”. Revista Chilena de Derecho Privado, $\mathrm{N}^{\circ} 15$, p. 150). BARAONA (2014) 400 . 
en el incumplimiento de la norma; criterios propuestos por la causalidad adecuada resultan más aceptables y propios, en palabras de Araya ${ }^{60}$.

No obstante escapar el objeto de este estudio, hacemos referencia -con mero afán ilustrativo- a que el artículo 50 de la LDPC se refiere a la necesidad de acreditar el dańo y el vínculo contractual que liga al infractor y a los consumidores afectados. Refrendando la idea que aquel constituye un caso de regulación en especifico de la ley, pues, como se ha justificado en párrafos que preceden, la existencia de un contrato servirá solo como antecedente o soporte de lo específico y que norma la LDPC, esto es, el hecho del consumo, toda vez que existirán situaciones o conductas del proveedor que afecten el ejercicio de derechos de los consumidores donde no se ha celebrado contrato, pero seguirán resguardado sus derechos. En este sentido, Baraona ${ }^{61}$ afirma que no se hace referencia al nexo causal, que debería concurrir entre incumplimiento y daño conforme a los cánones clásicos, esto a propósito de que la vulneración del contrato o la obligación que dio origen al hecho del consumo es solo un presupuesto que desata la responsabilidad.

\section{4) POR QUÉ NO DEBEMOS ACUdIR A LAS FUENTES TRADICIONALES}

Hemos pretendido sentar las bases de un nuevo entendimiento de la responsabilidad civil en la LDPC a partir del hecho del consumo, pero creemos necesario para sustentar esta idea, confrontarla con las fuentes tradicionales.

\section{(4.1.) LA HIPÓTESIS DE INCUMPLIMIENTO CONTRACTUAL}

Desde ya discrepamos que el contrato como acto jurídico bilateral sea principal y exclusivamente el generador de las obligaciones que establece y protege LDPC. En este sentido, no compartimos la opinión de $V_{\text {Vidal }}{ }^{62}$, cuando afirma que la relación jurídica de consumo se materia-

60 Afirma "y es que de acuerdo con esta concepción, se reintroduce en la responsabilidad la idea de previsibilidad del daño, toda vez que se responde solo de las consecuencias producidas según el curso normal de las cosas". (AraYa, Fernando (2003) La relación de causalidad en la responsabilidad civil. Santiago: LexisNexis, p. 63).

61 BARAONA (2014) 401.

62 Vidal Olivares, Álvaro Rodrigo (2000) "Contratación y consumo, el contrato de consumo en la ley $\mathrm{N}^{\circ} 19.496$ sobre protección a los derechos de los consumidores". Revista de Derecho de la Universidad Católica de Valparaíso, p. 230. 
liza en un acto jurídico -contrato-, si por ello asumimos una derivación jurídica explicada en términos de derechos y obligaciones y no como un mero presupuesto fáctico, que es lo que nosotros sostenemos ${ }^{63}$.

De lo expresado fluye un origen diverso de las obligaciones. Así, en el contrato serán las partes las que mediante su consentimiento dan origen a las obligaciones recíprocas, siendo el contrato la fuente de estas ${ }^{64}$, por su parte, afirmamos que en el caso del acto de consumir, es la Ley la fuente de la que emanarían las obligaciones de proveedor y consumidor, y el acto jurídico que puede servirle de soporte material es eso, un mero presupuesto de aplicación de la norma.

Siguiendo con la misma línea de estudio, tampoco para el caso de incumplimiento por parte del proveedor aparecen los elementos propios de la responsabilidad contractual, tal como lo afirma Baraona ${ }^{65}$. Luego, concluimos que es la LDPC, dispersamente, la que va indicando según los variados casos, cuáles son los deberes y derechos de las partes en el consumo y no el contrato ${ }^{66}$. Lo anterior es comprendido sin perjuicio de una eventual concurrencia de responsabilidad, en cuyo caso deberá ser el consumidor quien opte por demandar según más convenga a sus intereses.

\section{(4.2.) OBLIGACIONES LEgALES Y RÉGIMEN EXTRACONTRACTUAL}

Siendo la ley la que da vida a los derechos y obligaciones de consumidor y proveedor en el consumo, surge la pregunta de si para el caso en que el proveedor incumpla una obligación de aquellas que la LDPC le impone ¡es el régimen extracontractual el que se debe aplicar teniendo como supuesto de base de la obligación el cuasidelito civil, esto es, que el proveedor actúe negligentemente? Salvo las normas citadas como la del artículo $23^{67}$ de la citada ley, no es presupuesto o requisito el imputar

63 Stiglitz, Rubén Saúl (2010) Contratos civiles y comerciales: parte general. Buenos Aires: Editorial La Ley, 2da edición actualizada y ampliada, p. 7.

64 Alessandri Rodríguez, Arturo (2011) De los contratos. Santiago: Editorial Jurídica de Chile, p. 5.

65 BARAONA (2014) 381-408.

66 Al efecto, en palabras del referido autor "el contrato que sustenta el acto de consumo, se convierte en un elemento o instrumento que sirve de cause para generar la responsabilidad, pero no es estrictamente el aspecto central" (BARAONA (2014) 397).

67 "Artículo 23.- Comete infracción a las disposiciones de la presente ley el proveedor que, en la venta de un bien o en la prestación de un servicio, actuando con negligencia, causa menoscabo al consumidor debido a fallas o deficiencias en la calidad, cantidad, identidad, sustancia, procedencia, seguridad, peso o medida del respectivo bien o servicio.

Serán sancionados con multa de cien a trescientas unidades tributarias mensuales, los organizadores de espectáculos públicos, incluidos los artísticos y deportivos, que pongan 
negligencia o malicia al proveedor en el incumpliendo de la ley. En efecto, solo en caso como el de la norma del artículo 23 está la exigencia de negligencia como presupuesto de la responsabilidad del proveedor, quien únicamente en el acto de venta de un bien o en la prestación de un servicio cause menoscabo al consumidor en los casos que se prevén, tratándose, para Corral ${ }^{68}$, de una responsabilidad civil basada en la culpa ${ }^{69}$. Una situación inversa se presenta en Argentina cuando se establece la responsabilidad de todos los sujetos de la cadena de comercialización, incluido el revendedor minorista, sin que se requiera la culpa de este.

Teniendo presente que la responsabilidad extracontractual supondrá incumplimiento legal, daño, factor de imputación y relación causal entre el incumplimiento y el daño en el hecho del consumo, si se revisa cada una de las normas en que la Ley impone al proveedor alguna obligación, salvo excepcionados casos como el de la norma citada o del artículo 28, no se requiere que aquel sea negligente o malicioso, es decir, que actúe con culpa o dolo. De esta manera, no hay un factor subjetivo que impere en la conducta transgresora del proveedor, más bien estamos frente a un hecho objetivo.

Para Corral $^{70}$, si se trata de obligaciones legales, la normativa a aplicar será la de la responsabilidad extracontractual destinada a regular los casos de violación del principio jurídico general, como el de no dañar injustamente a otro. En igual sentido, Barros ${ }^{71}$, concluye que al no tener la obligación legal fuente en la convención ni su contenido puede estar determinado por las partes, ello supone que las condiciones y efectos de la responsabilidad son las de la extracontractual e indica que la responsabilidad por incumplimiento de obligaciones legales debe ser construida con criterios típicos de la responsabilidad extracontractual. Por último, para Rodríguez $^{72}$, si es la ley la que directamente asigna el deber de conducta, se tratará de una responsabilidad extracontractual.

en venta una cantidad de localidades que supere la capacidad del respectivo recinto. Igual sanción se aplicará a la venta de sobrecupos en los servicios de transporte de pasajeros, con excepción del transporte aéreo."

68 Corral (2011) 128.

69 "Tal como se advierte, este autor (Corral) invierte el régimen de responsabilidad de fabricante, transformando su responsabilidad naturalmente extracontractual en contractual, por la vía de aplicarle el régimen de incumplimiento legal de las normas de la LPDC.” (BARRIENTOS (2010) 5).

70 Corral (2013) 40.

71 Barros Bourie, Enrique (2006) Tratado de Responsabilidad Extracontractual. Santiago: Editorial Jurídica de Chile, p. 1070.

72 Rodríguez Grez, Pablo (2010) Responsabilidad extracontractual. Santiago: Editorial Jurídica de Chile, p. 12. 
De los autores mencionados discrepamos la reconducción que hacen de la responsabilidad legal a la extracontractual, sin hacer la salvedad que habrá casos de infracción de ley en que no sea requisito la existencia de un factor de imputación como sucede habitualmente en casos de aquel régimen. Estimamos que la especial relación que regula la LDPC -con los matices vistos, que como afirmamos la dejan al margen del sistema contractual como fuente obligatoria-, haría que, en concepto de los referidos autores tuviésemos que aplicar derechamente el régimen extracontractual ${ }^{73}$ sin mayor cuestionamiento. Pensamos que dicho sistema no encaja plenamente en este nuevo derecho, toda vez que se carece de un elemento propio de la responsabilidad extracontractual -negligencia o malicia-, en este sentido y solo para este punto, compartimos el parecer de Rodríguez $^{74}$ de que la responsabilidad legal no puede asimilarse en todas sus características a la responsabilidad delictual o cuasidelictual.

Ahora bien, en relación a la causalidad igualmente se presenta una diferencia con el régimen extracontractual donde imperioso es que exista un nexo entre incumplimiento y daño ${ }^{75}$, el que ha de probarse conforme a las normas generales. En esta línea han fallado nuestros tribunales ${ }^{76}$ al reconducir los casos de infracción y daños a la hipótesis del artículo 23 de la Ley en cuanto se le imputa negligencia al proveedor. Pero tratándose de la responsabilidad civil en la LDPC a propósito del consumo, estimamos

73 En este sentido Corral frente a la compatibilidad con otros regímenes de responsabilidad civil a propósito de los productos defectuosos indica que "puede decirse que el estatuto de responsabilidad por productos es un régimen complementario y facultativo respecto del derecho común" y luego agrega: "En consecuencia, el perjudicado podrá ejercer acciones contractuales como las de incumplimiento de obligaciones o la redhibitoria o de reducción del precio por vicios ocultos en la compraventa, o acciones extracontractuales como las de responsabilidad derivada de un delito o cuasidelito civil". (Corral (2011) 193-194).

74 RODRÍGUEZ (2010) 36.

75 "desprendemos que la exigencia de nexo causal, trátese de responsabilidad contractual o extracontractual, objetiva o subjetiva o diga relación con el daño patrimonial o moral, no es discutida en la jurisprudencia chilena. Más aun, en ciertas ocasiones, nuestros tribunales han exigido ese elemento de manera expresa" (AraYa (2003) 181).

76 Corte de Apelaciones de Valparaíso. 2 de diciembre de 2013. Rol 473-2013. "Cavagnaro con Johnson's". Disponible en: http://corte.poderjudicial.cl/SITCORTEPORWEB/ DownloadFile.do?TIP_Documento=3\&TIP_Archivo=1\&COD_Opcion=1\&COD_ Corte $=30 \&$ CRR_IdTramite $=9409093 \&$ CRR_IdDocumento $=8174307$ [fecha de visita 21 de junio de 2016], p. 3; Corte De Apelaciones de Santiago. 2 de octubre de 2008. Rol 10.769-2004. "Diéguez con Falabella". Disponible en: http://corte.poderjudicial.cl/ SITCORTEPORWEB/DownloadFile.do?TIP_Documento $=3 \&$ TIP_Archivo $=3 \& C O D$ Opcion $=1 \&$ COD_Corte $=90 \& C R R \_I d T r a m i t e=1035935 \& C R R \_I d D o c u m e n t o=947887$ [fecha de visita 21 de junio de 2016], p. 10; Corte de Apelaciones de La Serena. 11 de diciembre de 2008. Rol: 181-2008. "Araya con Cencosud". Disponible en: http:// corte.poderjudicial.cl/SITCORTEPORWEB/DownloadFile.do?TIP_Documento=3\&TIP_ Archivo=38COD_Opcion=1\&COD_Corte=25\&CRR_IdTramite=2919142\&CRR_IdDocumento=2461066 [fecha de visita 21 de junio de 2016], p. 11 . 
existe una causalidad normativa, bastando la culpa infraccional sin que sea necesaria la búsqueda de nuevos factores de imputación. La responsabilidad abarcará las consecuencias que se hallan en relación con la infracción de una norma legal, en este sentido, salvo disposición legal antes referida, la carga de la prueba de los factores de atribución de quien los alega acá desaparece.

Dentro del incumplimiento de la ley que puede acarrear responsabilidad por dańos, Cane ${ }^{77}$ cita o llama el "ilícito de infracción legal" cuyas reglas se ocupan de dos cuestiones, primero, definen cuándo, ante el silencio de la ley, la infracción de una disposición legal puede ser accionable en sede de daños; y segundo -si dicha infracción es susceptible de una acción de dańos- determina qué estándar de responsabilidad debe ser aplicado, si corresponde responsabilidad estricta o si se basa en una especie de culpa. En esta línea Rodríguez ${ }^{78}$ trata del "ilícito civil típico" pero dentro de la responsabilidad extracontractual -lo que no compartimos-, en que surge responsabilidad de la sola presencia de los presupuestos contenidos en la hipótesis definida en la norma jurídica.

Se trata en definitiva de establecer, siguiendo a Díez-Picazo ${ }^{79}$, abstracción del dato de que pueda tratarse de responsabilidad contractual o extracontractual, ya que frente a los hechos especiales que regula la LDPC se ha buscado hacer más fácil el derecho al resarcimiento a través de criterios de objetivación de responsabilidad, como ha sucedido en la legislación española con la Ley General para Defensa de los Consumidores y Usuarios.

\section{CONCLUSIONES}

Las particularidades del derecho de consumo, con principios propios, conllevan a estimar primeramente que estamos frente a una regulación normativa especial y no complementaria o supletoria de las normas

77 Cane, Peter (2011) Anatomía del Derecho de Daños. Trad. Daniel Arturo Carvallo Montes y Pablo Andrés Becerra Poblete. Santiago: Flandes Indiano, pp. 173-179.

78 "Los ilícitos típicos no requieren, entonces, de la reunión de todos los elementos analizados en lo precedente. Para hacer nacer la responsabilidad es suficiente con la capacidad del sujeto que incurre en la infracción legal y la existencia de un perjuicio. Los demás presupuestos de la responsabilidad delictual y cuasidelictual deben darse por establecidos con el solo quebrantamiento de la norma que tipifica el ilícito. El análisis, por tanto, debe limitarse a la constatación de que se ha desplegado la conducta descrita en la ley por parte de una persona capaz de responsabilidad extracontractual, y que se ha irrogado un perjuicio como consecuencia de aquel comportamiento". (RodríGuez (2010) 455-456). 
del derecho común. A partir de ahí, arribamos a conclusiones diversas a las que tradicionalmente se han sostenido en torno a la responsabilidad civil derivada de relaciones de consumo.

Cuando pensamos en el consumo como lo que es, un hecho y no un acto jurídico en sentido estricto, establecemos un criterio diverso al que si lo comprendiéramos como un contrato entre proveedor y consumidor, de compraventa si se quiere. Se trata en definitiva, de un hecho al que la ley atribuye consecuencias, donde la autonomía privada no está presente ni como fuente ni como regulación. Estando el énfasis de la LDPC en la protección del consumidor, resulta innecesario e inapropiado recurrir a criterios del derecho común, como la libertad contractual y autonomía privada, bastando los propios principios de aquella. Al ser así, demostramos que el sistema resarcitorio en esta rama especial del derecho es peculiar, ya que se funda en fuente legal y bajo criterios más cercanos a los objetivos.

El acto jurídico por el cual se adquiere, utiliza o disfruta de los bienes o servicios, en la gran mayoría de los casos, será el presupuesto para calificar el acto como de consumo, pero no para derivar de allí los derechos y obligaciones que se regulan en este sede, que son las que establece la Ley. Por ello podemos describir propiamente el consumo como un hecho o conditio iuris, pues, no interesa esta calificación más que para detectar la materia que debe ser regulada, mas no para derivar de ella derechos y obligaciones, basado en el acuerdo negocial.

La ventaja de este sistema es que creemos resulta acorde con el espíritu de la LDPC, en el sentido que se minimice el impacto en el consumidor de los abusos en que incurra el proveedor, garantizando el debido ejercicio de sus derechos al no incorporar cargas excesivas -como la prueba de culpa o dolo o de la relación causal conforme con los cánones clásicos-, que, en definitiva, desincentiven el accionar resarcitorio.

\section{BibLIOGRAFíA}

Abeliuk, René (2008) Las Obligaciones, Tomo I. Santiago: Editorial Jurídica de Chile, quinta edición actualizada.

Aimone Gibson, Enrique (2013) Protección de derechos del consumidor. Santiago: LegalPublishing-Thomson Reuters.

Alessandri Rodríguez, Arturo (1983) De la responsabilidad extracontractual en el derecho civil chileno. Santiago: Ediar Editores.

Alessandri Rodríguez, Arturo (2011) De los contratos. Santiago:

Editorial Jurídica de Chile. 
Araya, Fernando (2003) La relación de causalidad en la responsabilidad civil. Santiago: LexisNexis.

Barasi, Lodovico (1955) Instituciones de derecho civil. Trad. Haro y Faleón. T.I. Barcelona: Editorial Bosch.

Baraona González, Jorge (2014) "Regulación contenida en la ley 19.496 sobre protección de los derechos de los consumidores y las reglas del código civil y comercial sobre contratos: un marco comparativo". Revista Chilena de Derecho, 41.2.

Barrientos Camus, Francisca (2010) "La responsabilidad del fabricante bajo el artículo 23 de la ley de protección de los derechos de los consumidores y su relación con la responsabilidad civil del vendedor". Revista Chilena de Derecho Privado, N 14.

Barrientos Camus, Francisca (2011) "Derecho de consumo, comentarios de jurisprudencia". Revista Chilena de Derecho Privado, $\mathrm{N}^{\circ} 16$.

Barrientos Camus, Francisca (2014) "La articulación de remedios en el sistema de la responsabilidad civil del consumo". Revista de Derecho de la Pontificia Universidad Católica de Valparaíso, XLII.

Barros Bourie, Enrique (2006) Tratado de Responsabilidad Extracontractual. Santiago: Editorial Jurídica de Chile.

Botana García, Gema y Llamas Pombo, Eugenio (2005) Ley para la defensa de los consumidores y usuarios. Madrid: La Ley.

Cámara Lapuente, Sergio (2011) Comentarios a las normas de protección de los consumidores. Madrid: Colex.

Cane, Peter (2011) Anatomía del Derecho de Daños. Trad. Daniel Arturo Carvallo Montes y Pablo Andrés Becerra Poblete. Santiago: Flandes Indiano.

Caprile Biermann, Bruno (2006) Las acciones del comprador insatisfecho: el cúmulo actual y la tendencia al deber de conformidad. Santiago: Editorial LexisNexis.

Contardo, Juan Ignacio (2013) La Protección de los derechos de los consumidores, comentario artículo $3^{\circ}$ letra e). Santiago: Thomson Reuters.

Corral Talciani, Hernán (2011) Responsabilidad por Productos Defectuosos, Análisis y Propuestas para El Derecho Civil y de Consumo en Chile. Santiago: Editorial AbeledoPerrot-LegalPublishing.

Corral Talciani, Hernán (2013) Lecciones de Responsabilidad Civil Extracontractual. Santiago: Editorial Legal Publishing.

De Cupis, Adriano (1970) El daño. Teoría general de la responsabilidad civil. Barcelona: Casa Editorial.

De la Maza, Íñigo (2012) Consumidores: El suministro de información como técnica de protección de los consumidores: los deberes precontractuales de información. Santiago: Thomson Reuters. 
Díez-Picazo, Luis (1979) Responsabilidad civil hoy. Madrid: Anuario de derecho civil, tomo 32 fascículo IV, octubre-diciembre.

Díez-Picazo, Luis (1999) Derecho de daño. Madrid: Civitas.

Domínguez Águila, Ramón (1990) "Consideraciones en torno al daño en la responsabilidad civil. Una visión comparatista”. Revista de Derecho Universidad de Concepción, $\mathrm{N}^{\circ} 188$.

Domínguez, Carmen (2006) "El daño moral en Chile: contornos y problemas". Anales de Derecho Pontificia Universidad Católica de Chile, $\mathrm{N}^{\circ} 1$.

Ducci Claro, Carlos (1995) Derecho Civil, parte general. Santiago: Editorial Jurídica de Chile, Cuarta Edición.

Fernández Fredes, Francisco (2003) Manual de derecho chileno de protección al consumidor. Santiago: LexisNexis.

Guerrero Becar, José Luis (2008) La distinción entre contravención infraccional e incumplimiento contractual o contravención civil en materia de protección de derechos del consumidor. Valparaíso: Ediciones Universitarias de Valparaíso.

Isler Soto, Erika (2014) "Comentario de sentencia sobre el concepto de consumidor". Revista Chilena de Derecho y Ciencia Politica.

Kemelmajer Carlucci, Aída (2001) "Los dilemas de la responsabilidad civil". Revista Chilena de Derecho, Vol. 28, № 44.

Lara González, Rafael et al. (2006) Consumo y derecho. Madrid: Editorial Esic.

Lorenzzetti, Ricardo (2004) Tratado de los contratos, parte general. Tomo I. Buenos Aires: Editorial Rubinzal y Culzoni.

Manzano Chávez, Liliana (2008) Defensa del consumidor. Analisis comparado de los casos de Argentina, Brasil, Chile y Uruguay. Santiago: Friedrich Ebert Stiffung. Disponible en: http://library.fes.de/pdffiles/bueros/chile/05458.pdf.

Meza Barros, Ramón (1997) Manual de derecho civil, de las obligaciones. Santiago: Editorial Jurídica de Chile.

Momberg Uribe, Rodrigo (2004) "Ámbito de aplicación de la ley $\mathrm{N}^{\circ}$ 19.496 sobre protección de los derechos de los consumidores". Revista de Derecho de la Universidad Austral de Chile, Vol. XVII.

Momberg Uribe, Rodrigo (2013) La Protección de los derechos de los consumidores, comentario artículo $1^{\circ}$ ). Santiago: Thomson Reuters.

Montiel Gómez, Adolfo (1966) El hecho jurídico. Santiago: Imprenta Editorial El Sur.

Pinochet Olave, Ruperto (2007) iIntegra el derecho de consumo el derecho civil, el derecho mercantil o conforma una disciplina jurídica autónoma?. En Estudios de Derecho Civil III, Jornadas Nacionales de derecho civil Valparaíso. Santiago: Editorial Legal Publishing. 
Pizarro Wilson, Carlos (1999) La protección de los consumidores en materia contractual. Santiago: Editorial Jurídica ConoSur.

Prevot, Juan Manuel (2010) "El problema de la relación de causalidad en el derecho de la responsabilidad civil". Revista Chilena de Derecho Privado, $\mathrm{N}^{\circ} 15$.

Rodríguez Grez, Pablo (2010) Responsabilidad extracontractual. Santiago: Editorial Jurídica de Chile.

Rodríguez Grez, Pablo (2014) "¿Puede hablarse de un derecho del consumidor?". Revista Actualidad Jurídica, No 29.

Rodríguez Grez, Pablo (2015) "¿Puede hablarse de un derecho del consumidor?". Revista Actualidad Jurídica, Nº 31.

Stiglitz, Rubén Saúl (2010) Contratos civiles y comerciales: parte general. Buenos Aires: Editorial La Ley, 2da edición actualizada y ampliada.

Tomasello Hart, Leslie (1994) Estudios de derecho privado. Valparaíso: EDEVAL.

Vial del Río, Víctor (2003) Teoría general del acto jurídico. Santiago: Editorial Jurídica de Chile.

Villalba Cuéllar, Juan Carlos (2009) Aspectos introductorios al derecho del consumo. Bogotá: Red de Revistas Científicas de América Latina y el Caribe, España y Portugal.

Vidal Olivares, Álvaro Rodrigo (2000) "Contratación y consumo, el contrato de consumo en la ley $\mathrm{N}^{\circ} 19.496$ sobre protección a los derechos de los consumidores". Revista de Derecho de la Universidad Católica de Valparaíso.

Yuseff, Gonzalo (2000) Responsabilidad civil y responsabilidad objetiva. Santiago: La Ley.

\section{JURISPRUDENCIA CITADA}

Corte de Apelaciones de Concepción. 24 de diciembre de 2007. Rol 174-2005. "Arias con Sodimac". Disponible en: ht tp: / / corte.poderjudicial.cl/SITCORTEPORWEB/ DownloadFile.do?TIP_Documento=3\&TIP_Archivo=3\&COD_ Opcion $=1 \&$ COD_Corte $=46 \&$ CRR_IdTramite $=3817592 \&$ CRR_ IdDocumento $=3093484$

Corte de Apelaciones de Santiago. 2 de octubre de 2008. Rol 10.7692004. "Diéguez con Falabella". Disponible en

http://corte.poderjudicial.cl/SITCORTEPORWEB/DownloadFile. do ? T I P _ D o cumento=3\&TIP_Archivo=3\&COD_ Opcion $=1 \&$ COD_Corte $=90 \&$ CRR_IdTramite $=1035935 \&$ CRR_ IdDocumento $=947887$ 
Corte de Apelaciones de La Serena. 11 de diciembre de 2008. Rol: 181-2008. "Araya con Cencosud". Disponible en

http://corte.poderjudicial.cl/SITCORTEPORWEB/DownloadFile. do? TIP_D ocumento=3\&TIP_Archivo=3\&COD_ Opcion $=1 \&$ COD_Corte $=25 \&$ CRR_IdTramite $=2919142 \&$ CRR_ IdDocumento $=2461066$

Corte de Apelaciones de Santiago. 5 de enero de 2008. Rol: 9663 2008. "Cabello con Hipermercado Alameda". Disponible en http://corte.poderjudicial.cl/SITCORTEPORWEB/DownloadFile. do ? T I P_D ocumento $=3 \&$ T I P _ Archivo $=3 \& \mathrm{COD}_{-}$ Opcion=1\&COD_Corte $=90 \&$ CRR_IdTramite $=1065445 \&$ CRR_ IdDocumento $=972900$

Corte Suprema. 24 de abril de 2013. Rol 12.355-2011. "Sernac con Cencosud". Disponible en http://suprema.poderjudicial.cl/ SITSUPPORWEB/InicioAplicacion.do

Corte de Apelaciones de Valparaíso. 2 de diciembre de 2013. Rol 473-2013. "Cavagnaro con Johnson's”. Disponible en

http://corte.poderjudicial.cl/SITCORTEPORWEB/DownloadFile. do ? T I P_D ocumento $=3 \&$ T I P _ Archivo $=1 \& \mathrm{COD}_{-}$ Opcion $=1 \&$ COD_Corte $=30 \&$ CRR_IdTramite $=9409093 \&$ CRR_ IdDocumento $=8174307$. 